\title{
Review
}

\section{Rationale for Randomized Clinical Trials Investigating the Potential of BCG Vaccination in Preventing COVID-19 Infection}

\author{
Magali Noval Rivas ${ }^{\mathrm{a}, \mathrm{b}}$, Charles J. Rosser ${ }^{\mathrm{c}, 1}$ and Moshe Arditi ${ }^{\mathrm{a}, \mathrm{b}, \mathrm{d}, 1, *}$ \\ ${ }^{a}$ Department of Pediatrics, Division of Infectious Diseases and Immunology, Infectious and Immunologic \\ Diseases Research Center (IIDRC) and Department of Biomedical Sciences, Cedars-Sinai Medical Center, \\ Los Angeles, CA, USA \\ ${ }^{\mathrm{b}}$ Department of Pediatrics, David Geffen School of Medicine at UCLA, Los Angeles, CA, USA \\ ${ }^{\mathrm{c}}$ Samuel Oschin Comprehensive Cancer Institute, Cedars-Sinai Medical Center, Los Angeles, CA, USA \\ ${ }^{\mathrm{d}}$ Smidt Heart Institute, Cedars-Sinai Medical Center, Los Angeles, CA, USA
}

Received 11 December 2020

Accepted 4 February 2021

Pre-press 23 February 2021

Published 25 May 2021

\begin{abstract}
Despite the implementation of mitigation measures, Coronavirus disease 2019 (COVID-19), caused by severe acute respiratory syndrome coronavirus 2 (SARS-CoV-2), is still spreading worldwide, and has caused more than 1 million deaths so far. Although recent reports indicate that three vaccine candidates are effective against SARS-CoV-2, more time is needed to generate enough doses for the general population. Meanwhile, frontline healthcare workers are at high risk of SARS-CoV-2 exposure. To avoid collapse of the medical care system, there is a need to develop novel approaches to limit SARS-CoV-2 spread. Through a process called trained immunity, the Bacillus Calmette-Guerin (BCG) vaccine boosts the action of innate immune cells, resulting in a nonspecific reduction in the incidence of viral infections. Due to this immunomodulatory action, the BCG vaccine is currently used as a therapeutic in bladder cancer. Data collected from epidemiological and observational studies indicate that BCG vaccination might provide protection against COVID-19. While these observations do not provide evidence of causality and are limited by cofounding and intrinsic biases, it is crucial to explore the hypothesis that BCG vaccination may provide a nonspecific innate immune boost and therefore protect against COVID-19 in randomized controlled clinical trials, particularly for people at higher risk of developing COVID-19, such as frontline healthcare workers.
\end{abstract}

Keywords: BCG, SARS-COV-2, COVID-19, clinical trials

\footnotetext{
${ }^{1}$ These senior authors contributed equally

*Correspondence to: Moshe Arditi, Cedars-Sinai Medical Center, 8700 Beverly Blvd, Davis Building, Rooms D4024, 4035, 4027, Los Angeles, CA 90048, USA. E-mail: moshe.arditi@cshs. org.
}

\section{INTRODUCTION}

Coronavirus disease-2019 (COVID-19), caused by the novel severe acute respiratory syndrome coronavirus 2 (SARS-CoV-2), was first reported in December 2019 in Wuhan, China. SARS-CoV-2 is a beta-coronavirus closely related to SARS-associated 
coronavirus (SARS-CoV) and Middle Eastern Respiratory Syndrome (MERS-CoV) [1], and primarily targets the respiratory tract, causing disease ranging from common cold symptoms to a severe and fatal respiratory illness [2]. SARS-CoV-2 is highly transmissible and spreads via respiratory droplets or aerosols [3]. The most common COVID-19 clinical symptoms are fever, dry cough, loss of taste or smell, breathing difficulties and diarrhea [4]. Although the majority of SARS-CoV-2 infected individuals develop a mild disease, approximately 15 to $20 \%$ progress to a severe form of COVID-19 characterized by lung tissue damage, dyspnea, hypoxemia, respiratory failure and even death $[4,5]$. Elderly people as well as individuals with comorbidities and underlying diseases such as cardiovascular disease, diabetes, liver disease, kidney disease, or cancer are at higher risk of developing severe COVID-19 [4, 6, 7]. Severe COVID-19 is characterized by overactivation of the immune system and extensive release of proinflammatory cytokines, a process called cytokine storm, which results in a multisystem inflammatory syndrome, fatal in $28 \%$ of cases [2, 8]. Children are less affected by COVID-19, with the majority of SARS-CoV-2 infected children developing mild or no symptoms [9]. However, in rare occurrences, some infected children develop a multisystem inflammatory syndrome (MIS-C) characterized by fever, severe abdominal pain, diarrhea, myocardial dysfunction, and cardiogenic shock, which requires intensive care treatment [10-15].

Despite the implementation of public health measures aiming to reduce and mitigate the spread of SARS-CoV-2 in the most affected regions, as of midJanuary 2021, the COVID-19 pandemic has affected more than 95 million individuals and resulted in more than 2 million deaths worldwide [16]. Since early January 2020, when the genetic sequence of SARSCoV-2 was characterized, multiple efforts have been underway to develop specific vaccines against the virus [17]. Although promising results have emerged for three vaccines candidates (BNT162b2 vaccine from Pfizer/BioNTech, mRNA-1273 from Moderna and AZD1222 from AstraZeneca), additional time will be required to mass produce and globally distribute these vaccines. Hence, other preventive treatments are urgently needed to decrease the risk of SARS-CoV-2 infection in individuals experiencing high levels of exposure, such as healthcare workers, first responders, and essential workers, as well as those in high-risk groups, such as individuals over 65 years of age and those with comorbidities.
Bacillus Calmette-Guérin (BCG) is a live attenuated vaccine originally developed 100 years ago against Mycobacterium tuberculosis, and is currently used worldwide in newborns and infants to prevent tuberculosis. By modulating the phenotype and function of innate immune cells and promoting an innate immune memory, a process called trained immunity, BCG vaccine induces potent protection against other infectious agents (Fig. 1) [18]. Administration of BCG vaccination shortly after birth decreases child mortality, mainly as a result of reduced neonatal sepsis, fever and respiratory infections [19-21]. BCG-induced trained innate immune cells respond more rapidly and efficiently to secondary, nonrelated, stimuli. Exploiting nonspecific boosting of innate immunity through BCG vaccination might be a valuable preventive and protective strategy during the current pandemic, as BCG vaccine might partially or completely decrease SARS-CoV-2 infections and reduce the severity of COVID-19 (Fig. 1) [22, 23]. Epidemiological reports do indicate a possible negative correlation between COVID-19 mortality rates and BCG vaccination coverage [24-26], and observational studies associated BCG vaccination with decreased rates of SARS-CoV-2 infections [27-29]. BCG vaccination is safe, immunogenic, inexpensive and already available. However, before starting mass BCG vaccination, randomized clinical trials are required to determine its safety and efficacy as a firstline preventive therapy for COVID-19.

\section{Nonspecific immune boosting and protective effects of $B C G$ vaccination}

While BCG vaccination is effective against tuberculosis in children, its protective effects appear reduced and less effective in older individuals [30]. Clinical evidence strongly indicates that BCG vaccination beneficially and nonspecifically alters the host immune response to confer protection against unrelated infections. The first report of nonspecific immunity induced by BCG vaccination dates back from 1927, when a 2- to 3-fold decrease in all-cause mortality was observed among Swedish children who received the BCG vaccination at birth, compared with unvaccinated children [31]. This steep decrease of mortality rate could not be explained by a BCG-targeted effect against tuberculosis alone, as the protection was extended to many other respiratory illnesses and diarrheal diseases, and was more likely mediated by a BCG-induced nonspecific immunity and protection from other unrelated 


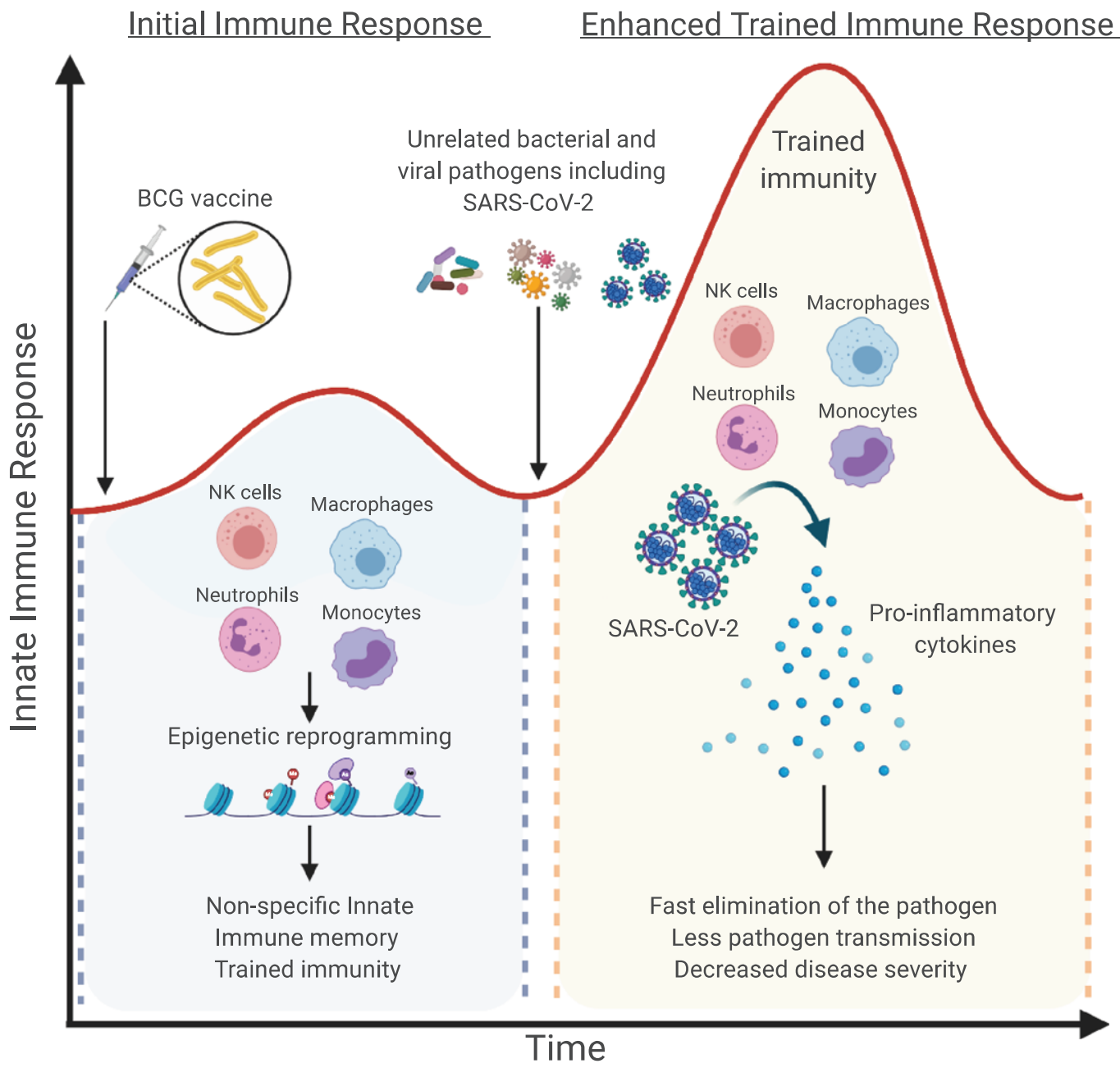

Fig. 1. How BCG-induced trained immunity could prevent SARS-CoV-2 infections. Bacillus Calmette-Guérin (BCG) vaccination or other microbial components can induce a heterologous immunological memory, a process defined as "trained immunity", which results in heightened innate immune responses upon exposure to secondary infections. BCG vaccination will initially stimulate innate immune cells, such as monocytes, macrophages, NK cells and neutrophils, and induce long-term metabolic and epigenetic reprograming resulting in increased responsiveness upon secondary stimulation with either the same or a different microbial ligand. In the context of COVID-19 pandemic, boosting innate immune cells by BCG vaccination and induction of trained immunity might provide nonspecific cross-protection against SARS-CoV-2 infection. Figure created with BioRender.com.

bacterial and viral diseases [31, 32]. Observational studies and randomized trials in West Africa further confirmed this observation, where BCG vaccination at birth significantly reduced neonatal mortality by decreasing the incidence of respiratory infections, neonatal sepsis, and fever [19, 20,33]. Additionally, a systematic review of 34 birth cohorts indicated lower risks of all-cause childhood mortality with BCG vaccination [34], and health survey data collected in low- and middle-income countries supports the protective role of BCG vaccination and its association with decreased risk of acute lower respiratory tract infections [35]. The nonspecific protective effects mediated by BCG vaccination, also called "offtarget" or "heterologous" effects, are not only limited to infants and children, and a recent study showed a $75 \%$ decrease in the incidence of upper respiratory tract infections in adolescents revaccinated with BCG compared to placebo [36]. In a randomized placebocontrolled human challenge study, BCG vaccination improved the anti-viral response against a vaccine strain of yellow fever, as demonstrated by decreased viremia in BCG-vaccinated participants [37]. This BCG-induced anti-viral response was mediated by trained immunity, characterized by epigenetic reprograming of circulating monocytes and upregulation 
of their IL-1 $\beta$ production upon restimulation, which correlated with viremia reduction [37].

One application of the nonspecific heterologous immunomodulatory properties of BCG vaccination is in the treatment of cancer, and the potential of BCG to prevent tumor growth has been investigated in various experimental animal models $[38,39]$. In a 60 year follow up of a BCG vaccination clinical trial, childhood BCG vaccination was associated with lower rates of lung cancer development [40], supporting the concept that early-life BCG vaccination might confer protection against cancer development later in life. BCG is also used therapeutically to treat cutaneous melanoma metastases, and BCG intralesional treatment induces regression of up to $90 \%$ of injected melanoma skin lesions and $17 \%$ of noninjected lesions [41, 42]. This effect appears to be mediated by trained immunity, as intralesional BCG induces transcriptional reprograming of melanoma skin lesions macrophages, improvement of their proinflammatory functions, and enhanced capacity to promote $\mathrm{T}$ cell activity in the tumoral microenvironment [43]. Intravesical instillation of BCG is also used as a nonspecific adjuvant in the treatment of non-muscle invasive bladder cancer and has been shown to delay disease progression and reduce disease recurrence [44-46]. This treatment is associated with increased immune cell infiltration in the bladder, as well as heightened urinary concentrations of pro-inflammatory cytokines and chemokines, which are typically associated with the trained immunity process [44].

BCG vaccination also appears to be beneficial in preventing Alzheimer's disease, as a retrospective study indicates decreased risk of developing Alzheimer's disease in patients with bladder cancer treated with BCG intravesical instillations [47]. Although the immune mechanisms involved in this protective effect still need to be characterized, it has been shown that BCG immunization decreases cognitive dysfunction and neuroinflammation in a transgenic murine model of Alzheimer's disease, associated with the recruitment of inflammationresolving macrophages to brain tissues [48].

\section{Immune mechanisms involved in BCG-induced trained immunity}

Trained immunity can be triggered by a primary infection or vaccination, is regulated by epigenetic and metabolic modifications, and results in longterm functional reprograming of innate immune cells (Fig. 1) [18, 49]. This functional reprogramming enhances the ability of innate immune cells to efficiently respond upon secondary stimulation by microbial pathogens, and eliminate the infection independently of $\mathrm{T}$ and $\mathrm{B}$ cells $[18,49]$. By enhancing nonspecific immune resistance to reinfection, trained immunity also provides cross-protection against different pathogens.

Evidence of BCG-induced trained immunity has been demonstrated in murine models. For example, mice vaccinated with $\mathrm{BCG}$ are protected against secondary infection with either Candida albicans or Schistosoma mansoni [50, 51]. This effect does not rely on the adaptive immune system, as severe combined immunodeficiency (SCID) mice, which lack $\mathrm{T}$ and $\mathrm{B}$ cells, are still protected from secondary candidiasis [52]. Trained immunity has been described in various innate immune cell subsets, such as macrophages, monocytes, natural killer (NK) cells and neutrophils [18, 49, 53]. Indeed, peripheral blood mononuclear cells (PBMCs) collected from BCG-vaccinated healthy volunteers and stimulated ex vivo with an unrelated pathogen demonstrate increased production of pro-inflammatory cytokines, such as IFN- $\gamma$, IL- $1 \beta$ and TNF- $\alpha$, up to 3 months post-BCG vaccination [52]. This response is mediated by epigenetic changes at the level of histone methylation (Histone H3 lysine 4, H3K4), which result in increased transcription of proinflammatory cytokines genes and long-term modulation of circulating monocytes [52]. Trained immunity also acts on NK cells; circulating NK cells isolated from BCG-vaccinated individuals demonstrate increased production of pro-inflammatory cytokines after ex vivo stimulation with either mycobacteria or an unrelated pathogen [54]. Furthermore, the nonspecific protection of BCG-vaccinated SCID mice against candidiasis is partially mediated by NK cell activity [54]. BCG vaccination also induces long-lasting phenotypic and functional reprograming of human circulating neutrophils, characterized by increased expression of activation markers and antimicrobial functions [53]. This reprogramming has been observed up to 3 months post-BCG vaccination [53].

Trained immunity is the main immunological mechanism by which BCG vaccination exerts its nonspecific cross-protection against other infectious agents. Therefore, through trained immunity, the BCG vaccine could potentially be used to help prevent epidemics, such as COVID-19, while specific vaccines are under development. 
Epidemiological studies hinting the protective effect of BCG vaccine for SARS-CoV-2 infections

The decrease in tuberculosis incidence in developed countries has resulted in the application of different guidelines regarding BCG vaccination from one country to another. In some areas BCG vaccination is still part of a current national vaccination policy, in others BCG was once administered broadly but is now only given to specific groups of high risk individuals, and in some countries BCG has never been part of a vaccination policy [55]. Since BCG vaccination confers some nonspecific crossprotection against respiratory infections, it was initially postulated that history of BCG vaccination might underlie some of the variability in COVID-19 infection and death rates from country to country. However, the results from recent epidemiological studies are variable, with some supporting and others refuting this hypothesis. For example, a study analyzing SARS-CoV-2 infection rates in a cohort of individuals born 3 years before or 3 years after the end of the Israeli universal BCG vaccination program found no difference in the rates of SARS-CoV-2 positivity, and concluded that childhood BCG vaccination does not prevent SARS-CoV-2 infection in adults [56]. When comparing BCG vaccination policies with COVID-19 mortality in individuals older than 65 years from middle-high and high-income countries, COVID-19-related death rate appears to be reduced in countries with a previous universal BCG vaccination policy [26]. In this study, which has not undergone peer review, the consideration of only high- and middle-income countries aimed to avoid biases in COVID-19 statistics, and is based on the assumption that the countries selected would provide reliable reports of COVID-19 associated death rate [26]. Indeed, epidemiological analysis of the potential beneficial effects of BCG vaccination against COVID-19 need to account for cofounding variables. The cumulative number of confirmed SARS-CoV2 infections and COVID-19-related deaths reported in each country might be influenced by reporting bias, differential testing capacities, absence of testing for asymptomatic SARS-CoV-2 infected individuals, and different methods of assessing the number of COVID-19-related deaths [25].

After accounting for multiple cofounding factors in their analysis, including the level of urbanization, population density, age, access to education and medical care, Escobar et al. reported strong associations between BCG vaccination and reduced COVID-19 deaths [24]. In a separate study, by considering only the day-by-day increase of COVID-19 confirmed cases and deaths, comparing the growth rate between countries which had a BCG vaccination policies with those that did not, and controlling for different cofounding factors, Berg at al. demonstrated a significant effect of mandated BCG policies on the growth of the pandemic as well as COVID-19 spread and deaths [25]. In an observational retrospective analysis of healthcare workers from the Los Angeles area, we showed that compared with healthcare workers that were not non-BCG vaccinated, history of BCG vaccination was associated with decreased self-reports of COVID-19 related symptoms and reduced seroprevalence of anti-SARS-CoV-2 antibodies [29]. This beneficial effect against SARS-CoV-2 infection was only observed in those with history of BCG vaccination and was not associated with other types of vaccination, such as influenza, meningococcal and pneumococcal [29]. In a cross-sectional study of Indian healthcare workers, the seroprevalence of SARSCoV-2 antibodies was also reduced in individuals that reported BCG vaccination during childhood [28]. Another retrospective study on COVID-19 patients from a Rhode Island hospital indicated that BCG vaccination is associated with decreased risk of hospital admission during the course of COVID-19 [27].

In summary, these retrospective analyses suggest that $\mathrm{BCG}$ vaccination might exert a protective effect against SARS-CoV-2 infection and decrease COVID19 related mortality. However, these reports are observational, and they cannot demonstrate a causal relationship between $B C G$ vaccination and decreased rate of SARS-CoV-2 infection and COVID-19 mortality. Another caveat is that these studies may not reveal the potential of BCG vaccine given acutely to prevent SARS-CoV-2 infection, as in most cases the study participants were vaccinated as children, so their trained immunity may have faded. Only results obtained from randomized clinical trials will provide clear evidence of whether BCG vaccination is beneficial against SARS-CoV-2 infection. This strategy may be the best suited to protect individuals at the highest risk, such elderly people and others with comorbidities, and those who face the greatest exposure, such as frontline healthcare workers.

\section{$B C G$ vaccine as a preventive treatment for SARS-CoV-2 infection}

SARS-CoV-2 is spreading rapidly throughout the world, and as of December 2020 many countries are 
experiencing second and third waves of infections associated overwhelmed healthcare systems and elevated mortality due to COVID-19. Results from a prospective observational cohort study in the UK and USA indicate that, compared with the general population, frontline healthcare workers are at higher risk of SARS-CoV-2 exposure and at increased chances of testing positive for COVID-19 [57]. This risk is also influenced by other factors such the lack of adequate personal protective equipment, the clinical setting and the ethnic background of healthcare workers [57]. There is a need to continue SARS-CoV-2 mitigation efforts and to prevent infections among healthcare workers. However, since effective SARS-CoV-2 vaccines are currently not yet widely available, additional prevention strategies need to be developed. Observational and epidemiological studies hinting at a potential beneficial effect of BCG vaccination against SARS-CoV-2 infection warrant the development of clinical trials to test this strategy. There are currently 22 ongoing interventional randomized clinical trials worldwide designed to determine if BCG vaccination can prevent SARS-CoV-2 infection, the majority aiming to assess the benefits of BCG vaccination in healthcare workers or elderly individuals (https://ClinicalTrials.gov) (Table 1).

The clinical trials may also lead to a more detailed characterization of the immunological mechanisms involved in the nonspecific BCG protective effect against unrelated viral infections. Through trained immunity, the BCG vaccine may boost innate immune responses, resulting in reduced SARS-CoV2 viremia, increased IL- $1 \beta$ production and faster viral elimination [22, 23]. By inducing epigenetic changes, BCG vaccination could also functionally reprogram mature human neutrophils and increase their expression of activation markers and their antimicrobial functions [53]. Patients with severe COVID-19 exhibit dysfunctional cytotoxic immune responses, as demonstrated by reduced numbers of circulating NK cells and $\mathrm{CD} 8^{+} \mathrm{T}$ cells $[58,59]$. By boosting NK cell function and proinflammatory cytokine production, BCG vaccination might ameliorate the dysfunctional cytotoxic immune responses observed during COVID-19. Pre-existing T cells able to cross-react with SARS-CoV-2 have been identified in healthy individuals that were not previously exposed to SARS-CoV-2, likely due to previous exposures to other coronaviruses [60-63]. The effect of such pre-existing memory SARS-CoV-2 cross reactive T cells on COVID-19 remains to be elucidated, however those cells could potentially be involved in viremia control and promote a more rapid production of anti-SARS-CoV-2 antibodies [64]. An additional proposed mechanism suggests that the $\mathrm{BCG}$ vaccine also activates $\mathrm{CD} 4^{+} \mathrm{T}$ cells and production of IFN- $\gamma$ [65], and interestingly, in silico computational studies identified a 9-amino acid sequence shared between BCG and SARS-CoV-2, indicating that BCG vaccination might also result in the induction of $\mathrm{T}$ cells capable to cross-react with SARS-CoV-2 [66].

BCG vaccination is considered safe, even in latently infected adults with prior infant BCG vaccination $[36,67,68]$. BCG vaccination is also safe in elderly individuals, as no difference in the rate of adverse effects and no increase in the levels of pro-inflammatory cytokines at steady-state were observed between the BCG-vaccinated and placebo group in the ACTIVATE clinical trial [69]. Promising results were reported from the interim analysis of the double-blind Phase III ACTIVATE clinical trial, which investigated the benefit of BCG vaccination against other non-tuberculosis infectious diseases on patients older than 65 years [69]. BCG vaccination in elderly individuals led to a strong reduction in the incidence of new respiratory tract infections, which appeared to be mediated by trained immunity, as cytokine production by PBMCs isolated from elderly BCG-vaccinated individuals when exposed to an unrelated stimulus [69].

BCG vaccination induces long-term metabolic changes and epigenetic reprograming of monocytes, macrophages and NK cells, which boost their antimicrobial responses and promote host resistance upon exposure to unrelated infectious agents [49]. However, non-infectious agents, such as microbial products or endogenous stimuli, can also improperly elicit trained immunity, amplify innate immune responses and detrimentally contribute to tissue damage and the development of certain inflammatory diseases $[18$, 70, 71]. COVID-19 development is linked to dysregulated immune responses, and in up to $20 \%$ of infected individuals, SARS-CoV-2 infection results in hyperinflammation associated with high levels of circulating inflammatory markers and excessive production of proinflammatory cytokines, which has been correlated with COVID-19 severity and death [72, 73]. Therefore, it might be possible that in the context of this COVID-19 pandemic, BCG vaccine could be deleterious by contributing to SARS-CoV-2-induced inflammatory responses. However, in a retrospective cohort study, recent BCG vaccination was shown to be safe during this COVID-19 pandemic, and associated with decreased incidence of sickness [74]. 
Table 1

List of randomized clinical trials evaluating the capacity of BCG vaccine to prevent COVID-19 in elderly or healthcare workers. Data collected from www.ClinicalTrials.org as of January 20, 2021

\begin{tabular}{|c|c|c|c|c|}
\hline NCT Number & Phases & Title & Sponsors & $\begin{array}{l}\text { Estimated } \\
\text { Completion }\end{array}$ \\
\hline NCT04475302 & Phase 3 & $\begin{array}{l}\text { BCG Vaccine in Reducing Morbidity and Mortality } \\
\text { in Elderly Individuals in COVID-19 Hotspots }\end{array}$ & $\begin{array}{l}\text { Tuberculosis Research } \\
\text { Centre, India }\end{array}$ & May 2021 \\
\hline NCT04632537 & Phase 3 & BCG Vaccination to Prevent COVID-19 (NUEVA) & $\begin{array}{l}\text { Henry M. Jackson Foundation } \\
\text { for the Advancement of } \\
\text { Military Medicine, USA }\end{array}$ & April 2023 \\
\hline NCT04379336 & Phase 3 & $\begin{array}{l}\text { BCG Vaccination for Healthcare Workers in } \\
\text { COVID-19 Pandemic }\end{array}$ & $\begin{array}{l}\text { TASK Applied Science, } \\
\text { South Africa }\end{array}$ & $4 / 28 / 21$ \\
\hline NCT04328441 & Phase 3 & $\begin{array}{l}\text { Reducing Health Care Workers Absenteeism in } \\
\text { Covid-19 Pandemic Through BCG Vaccine } \\
\text { (BCG-CORONA) }\end{array}$ & UMC Utrecht, Netherlands & $4 / 30 / 21$ \\
\hline NCT04350931 & Phase 3 & $\begin{array}{l}\text { Application of BCG Vaccine for } \\
\text { Immune-prophylaxis Among Egyptian Healthcare } \\
\text { Workers During the Pandemic of COVID-19 }\end{array}$ & Ain Shams University, Egypt & $12 / 1 / 20$ \\
\hline NCT04417335 & Phase 4 & $\begin{array}{l}\text { Reducing COVID-19 Related Hospital Admission in } \\
\text { Elderly by BCG Vaccination }\end{array}$ & $\begin{array}{l}\text { Radboud University, } \\
\text { Netherlands }\end{array}$ & May 2021 \\
\hline NCT04534803 & Phase 3 & $\begin{array}{l}\text { BCG Against Covid-19 for Prevention and } \\
\text { Amelioration of Severity Trial (BAC to the PAST) }\end{array}$ & $\begin{array}{l}\text { Harvard Medical School, } \\
\text { USA }\end{array}$ & $11 / 30 / 21$ \\
\hline NCT04537663 & Phase 4 & $\begin{array}{l}\text { Prevention of Respiratory Tract Infection and } \\
\text { Covid-19 Through BCG Vaccination In } \\
\text { Vulnerable Older Adults (BCG-PRIME) }\end{array}$ & UMC Utrecht, Netherlands & April 2021 \\
\hline NCT04327206 & Phase 3 & $\begin{array}{l}\text { BCG Vaccination to Protect Healthcare Workers } \\
\text { Against COVID-19 (BRACE) }\end{array}$ & $\begin{array}{l}\text { Murdoch Childrens Research } \\
\text { Institute, Australia }\end{array}$ & $3 / 30 / 22$ \\
\hline NCT04414267 & Phase 4 & $\begin{array}{l}\text { Bacillus Calmette-guérin Vaccination to Prevent } \\
\text { COVID-19 (ACTIVATE II) }\end{array}$ & $\begin{array}{l}\text { Hellenic Institute for the } \\
\text { Study of Sepsis, Greece }\end{array}$ & $5 / 25 / 21$ \\
\hline NCT04369794 & Phase 4 & $\begin{array}{l}\text { COVID-19: BCG As Therapeutic Vaccine, } \\
\text { Transmission Limitation, and Immunoglobulin } \\
\text { Enhancement (BATTLE) }\end{array}$ & $\begin{array}{l}\text { University of Campinas, } \\
\text { Brazil }\end{array}$ & August 2023 \\
\hline NCT04641858 & Phase 4 & $\begin{array}{l}\text { BCG to Reduce Absenteeism Among Health Care } \\
\text { Workers During the COVID-19 Pandemic } \\
\text { (EDCTP) }\end{array}$ & $\begin{array}{l}\text { University of Southern } \\
\text { Denmark }\end{array}$ & March 2022 \\
\hline NCT04461379 & Phase 3 & $\begin{array}{l}\text { Prevention, Efficacy and Safety of BCG Vaccine in } \\
\text { COVID-19 Among Healthcare Workers }\end{array}$ & $\begin{array}{l}\text { Hospital Universitario Dr. } \\
\text { Jose E. Gonzalez, Mexico }\end{array}$ & $1 / 1 / 21$ \\
\hline NCT04373291 & Phase 3 & $\begin{array}{l}\text { Using BCG Vaccine to Protect Health Care Workers } \\
\text { in the COVID-19 Pandemic }\end{array}$ & $\begin{array}{l}\text { Bandim Health Project, } \\
\text { University of Southern } \\
\text { Denmark }\end{array}$ & $8 / 1 / 21$ \\
\hline NCT04384549 & Phase 3 & $\begin{array}{l}\text { Efficacy of BCG Vaccination in the Prevention of } \\
\text { COVID19 Via the Strengthening of Innate } \\
\text { Immunity in Health Care Workers (COVID-BCG) }\end{array}$ & $\begin{array}{l}\text { Assistance Publique - } \\
\text { Hôpitaux de Paris, France }\end{array}$ & $2 / 20 / 21$ \\
\hline NCT04542330 & Phase 3 & $\begin{array}{l}\text { Using BCG to Protect Senior Citizens During the } \\
\text { COVID-19 Pandemic }\end{array}$ & $\begin{array}{l}\text { Bandim Health Project, } \\
\text { Denmark }\end{array}$ & March 2022 \\
\hline NCT04348370 & Phase 4 & $\begin{array}{l}\text { BCG Vaccine for Health Care Workers as Defense } \\
\text { Against COVID } 19 \text { (BADAS) }\end{array}$ & Texas A\&M University, USA & November 2021 \\
\hline NCT04439045 & Phase 3 & $\begin{array}{l}\text { Efficacy and Safety of VPM1002 in Reducing } \\
\text { SARS-CoV-2 (COVID-19) Infection Rate and } \\
\text { Severity (COBRA) }\end{array}$ & $\begin{array}{l}\text { University Health Network, } \\
\text { Toronto }\end{array}$ & $7 / 1 / 21$ \\
\hline NCT04387409 & Phase 3 & $\begin{array}{l}\text { Study to Assess VPM1002 in Reducing Healthcare } \\
\text { Professionals' Absenteeism in COVID-19 } \\
\text { Pandemic }\end{array}$ & $\begin{array}{l}\text { Vakzine Projekt Management } \\
\text { GmbH, Germany }\end{array}$ & $5 / 1 / 21$ \\
\hline NCT04435379 & Phase 3 & $\begin{array}{l}\text { Study to Assess VPM1002 in Reducing Hospital } \\
\text { Admissions and/or Severe Respiratory Infectious } \\
\text { Diseases in Elderly in COVID-19 Pandemic }\end{array}$ & $\begin{array}{l}\text { Vakzine Projekt Management } \\
\text { GmbH, Germany }\end{array}$ & $9 / 30 / 21$ \\
\hline NCT04659941 & Phase 2 & $\begin{array}{l}\text { Use of BCG Vaccine as a Preventive Measure for } \\
\text { COVID-19 in Health Care Workers (Pro-BCG) }\end{array}$ & $\begin{array}{l}\text { Universidade Federal do Rio } \\
\text { de Janeiro, Brazil }\end{array}$ & $10 / 01 / 22$ \\
\hline NCT04648800 & Phase 3 & $\begin{array}{l}\text { Clinical Trial Evaluating the Effect of BCG } \\
\text { Vaccination on the Incidence and Severity of } \\
\text { SARS-CoV-2 Infections Among Healthcare } \\
\text { Professionals During the COVID-19 Pandemic in } \\
\text { Poland (Pandemic in Poland) }\end{array}$ & $\begin{array}{l}\text { Hanna Czajka - Medical } \\
\text { Research Agency, Poland }\end{array}$ & April 2021 \\
\hline
\end{tabular}


Moreover, in a large cohort of healthy volunteers, BCG vaccine boosted the capacity of innate immune cells to mount antimicrobial responses and inhibited systemic inflammation in a sex-dependent manner, as demonstrated by decreased levels of circulating inflammatory markers post-BCG vaccination [75]. These observations suggest that the BCG vaccine does not exacerbate the development of inflammatory diseases, and further support the use of BCG vaccination as a preventive strategy for COVID-19. However only safety monitoring and results obtained from the ongoing randomized clinical trials testing BCG vaccination on healthcare workers will confirm whether the effects of BCG-induced trained immunity on COVID-19 are beneficial or deleterious [76]. These trials are also needed to further characterize the immune mechanisms involved. The results will not only benefit this current COVID-19 pandemic but may also be leveraged during future pandemic events while specific vaccines are under development.

Another potential challenge encountered with utilizing BCG vaccination as a COVID-19 preventative is the production of BCG vaccines in sufficient quantities to meet demand. Halts in BCG production owing to manufacturing issues associated with higher demand have resulted in BCG vaccines shortages over the last decade [77, 78]. However, positive results from randomized clinical trials assessing the capacity of BCG vaccination to protect from COVID-19 in healthcare workers may also stimulate BCG manufacturers to increase production. Such an outcome would also benefit patients with non-tuberculosis diseases for which BCG is used therapeutically, such as cutaneous metastatic melanoma and non-muscle invasive bladder cancer.

\section{CONCLUSIONS}

The ideal SARS-CoV-2 vaccine candidate will need to be safe and effective. At this stage of the SARS-CoV-2 clinical trials, it is still unclear whether the vaccine candidates will confer long-term protection against COVID-19 and be effective in the elderly. Recent reports indicate that three SARS-CoV-2 vaccine candidates display greater than $90 \%$ efficacy (BNT162b2 vaccine from Pfizer/BioNTech, mRNA1273 from Moderna. Recent studies indicates that the efficiency of this vaccine is $<70 \%$ not $90 \%$ ), however it is unclear when those vaccines will be available to the general public. BCG vaccination has been shown to induce nonspecific immunity against viral respiratory tract infections, and BCG is safe, available, immunogenic and inexpensive. Therefore, boosting innate immunity by BCG vaccination might provide protection against COVID-19 and support the healthcare system until a safe and effective specific SARS-CoV-2 vaccine is widely available. More than 22 clinical trials are currently underway to test the capacity of BCG vaccination to protect against COVID-19, some of which will release their results early 2021. It would be also interesting to investigate if patients with bladder cancer treated with intravesical BCG experience any protection against SARS-CoV-2 infection or reduced COVID-19 severity. These clinical trials are of high importance, as their results will determine not only the efficacy of BCG vaccination against non-tuberculosis infectious pathogens but will also determine if BCG vaccination would help boost the responses to the specific COVID-19 vaccines in specific populations, and if it could be used in the future as a first preventive measure for the next pandemic.

\section{ACKNOWLEDGMENTS}

The authors have no acknowledgments.

\section{FUNDING}

The others report no funding.

\section{AUTHOR CONTRIBUTIONS}

M.N.R.: reviewed the literature, wrote and critically revised the manuscript. C.J.R.: reviewed the literature, wrote and critically revised the manuscript. M.A: reviewed the literature, wrote and critically revised the manuscript.

\section{ETHICAL CONSIDERATIONS}

This study, as a literature review, is exempt from any requirement for Institutional Review Board approval.

\section{CONFLICT OF INTEREST}

MNR, CJR and MA have no conflicts of interest to report. 


\section{REFERENCES}

[1] Walls AC, Park YJ, Tortorici MA, Wall A, McGuire AT, Veesler D. Structure, Function, and Antigenicity of the SARS-CoV-2 Spike Glycoprotein. Cell. 2020;181(2):28192.e6.

[2] Vabret N, Britton GJ, Gruber C, Hegde S, Kim J, Kuksin $\mathrm{M}$, et al. Immunology of COVID-19: Current State of the Science. Immunity. 2020;52(6):910-41.

[3] Morawska L, Milton DK. It Is Time to Address Airborne Transmission of Coronavirus Disease 2019 (COVID-19). Clin Infect Dis. 2020;71(9):2311-3.

[4] Huang C, Wang Y, Li X, Ren L, Zhao J, Hu Y, et al. Clinical features of patients infected with 2019 novel coronavirus in Wuhan, China. Lancet. 2020;395(10223):497-506.

[5] Berlin DA, Gulick RM, Martinez FJ. Severe Covid-19. N Engl J Med. 2020;383(25):2451-60.

[6] Wang T, Du Z, Zhu F, Cao Z, An Y, Gao Y, et al. Comorbidities and multi-organ injuries in the treatment of COVID-19. Lancet. 2020;395(10228):e52.

[7] Guan WJ, Liang WH, Zhao Y, Liang HR, Chen ZS, Li YM, et al. Comorbidity and its impact on 1590 patients with COVID-19 in China: A nationwide analysis. Eur Respir J. 2020;55(5).

[8] Tay MZ, Poh CM, Rénia L, MacAry PA, Ng LFP. The trinity of COVID-19: Immunity, inflammation and intervention. Nat Rev Immunol. 2020;20(6):363-74.

[9] Lu X, Zhang L, Du H, Zhang J, Li YY, Qu J, et al. SARSCoV-2 Infection in Children. N Engl J Med. 2020;382(17): 1663-5.

[10] Riphagen S, Gomez X, Gonzalez-Martinez C, Wilkinson N, Theocharis P. Hyperinflammatory shock in children during COVID-19 pandemic. Lancet. 2020;395(10237):1607-8.

[11] Verdoni L, Mazza A, Gervasoni A, Martelli L, Ruggeri M, Ciuffreda M, et al. An outbreak of severe Kawasakilike disease at the Italian epicentre of the SARS-CoV-2 epidemic: An observational cohort study. Lancet. 2020; 395(10239):1771-8.

[12] Belhadjer Z, Méot M, Bajolle F, Khraiche D, Legendre A, Abakka S, et al. Acute Heart Failure in Multisystem Inflammatory Syndrome in Children in the Context of Global SARS-CoV-2 Pandemic. Circulation. 2020;142(5):429-36.

[13] Whittaker E, Bamford A, Kenny J, Kaforou M, Jones CE, Shah P, et al. Clinical Characteristics of 58 Children With a Pediatric Inflammatory Multisystem Syndrome Temporally Associated With SARS-CoV-2. Jama. 2020;324(3):259-69.

[14] Toubiana J, Poirault C, Corsia A, Bajolle F, Fourgeaud J, Angoulvant F, et al. Kawasaki-like multisystem inflammatory syndrome in children during the covid-19 pandemic in Paris, France: Prospective observational study. Bmj. 2020;369:m2094.

[15] Cheung EW, Zachariah P, Gorelik M, Boneparth A, Kernie SG, Orange JS, et al. Multisystem Inflammatory Syndrome Related to COVID-19 in Previously Healthy Children and Adolescents in New York City. Jama. 2020;324(3):294-6.

[16] WHO COVID-19 Dashboard. https://covid19whoint.

[17] Krammer F. SARS-CoV-2 vaccines in development. Nature. 2020;586(7830):516-27.

[18] Netea MG, Domínguez-Andrés J, Barreiro LB, Chavakis T, Divangahi M, Fuchs E, et al. Defining trained immunity and its role in health and disease. Nat Rev Immunol. 2020;20(6):375-88.

[19] Biering-Sørensen S, Aaby P, Napirna BM, Roth A, Ravn $\mathrm{H}$, Rodrigues A, et al. Small randomized trial among lowbirth-weight children receiving bacillus Calmette-Guérin vaccination at first health center contact. Pediatr Infect Dis J. 2012;31(3):306-8.

[20] Kristensen I, Aaby P, Jensen H. Routine vaccinations and child survival: Follow up study in Guinea-Bissau, West Africa. Bmj. 2000;321(7274):1435-8.

[21] Aaby P, Roth A, Ravn H, Napirna BM, Rodrigues A, Lisse IM, et al. Randomized Trial of BCG Vaccination at Birth to Low-Birth-Weight Children: Beneficial Nonspecific Effects in the Neonatal Period? The Journal of Infectious Diseases. 2011;204(2):245-52.

[22] O'Neill LAJ, Netea MG. BCG-induced trained immunity: Can it offer protection against COVID-19? Nat Rev Immunol. 2020;20(6):335-7.

[23] Netea MG, Giamarellos-Bourboulis EJ, DomínguezAndrés J, Curtis N, van Crevel R, van de Veerdonk FL, et al. Trained Immunity: A Tool for Reducing Susceptibility to and the Severity of SARS-CoV-2 Infection. Cell. 2020; 181(5):969-77.

[24] Escobar LE, Molina-Cruz A, Barillas-Mury C. BCG vaccine protection from severe coronavirus disease 2019 (COVID19). Proc Natl Acad Sci U S A. 2020;117(30):17720-6.

[25] Berg MK, Yu Q, Salvador CE, Melani I, Kitayama S. Mandated Bacillus Calmette-Guérin (BCG) vaccination predicts flattened curves for the spread of COVID-19. Sci Adv. 2020;6(32):eabc1463.

[26] Miller A, Reandelar MJ, Fasciglione K, Roumenova V, Li Y, Otazu GH. Correlation between universal BCG vaccination policy and reduced mortality for COVID-19. Medrxiv. 2020:2020.03.24.20042937.

[27] Weng CH, Saal A, Butt WW, Bica N, Fisher JQ, Tao J, et al. Bacillus Calmette-Guérin vaccination and clinical characteristics and outcomes of COVID-19 in Rhode Island, United States: A cohort study. Epidemiol Infect. 2020;148: e140.

[28] Goenka M, Afzalpurkar S, Goenka U, Das SS, Mukherjee M, Jajodia S, et al. Seroprevalence of COVID-19 Amongst Health Care Workers in a Tertiary Care Hospital of a Metropolitan City from India. J Assoc Physicians India. 2020;68(11):14-9.

[29] Noval Rivas M, Ebinger JE, Wu M, Sun N, Braun J, Sobhani $\mathrm{K}$, et al. BCG vaccination history associates with decreased SARS-CoV-2 seroprevalence across a diverse cohort of healthcare workers. J Clin Invest. 2021;131(2):e145157.

[30] Mangtani P, Abubakar I, Ariti C, Beynon R, Pimpin L, Fine PE, et al. Protection by BCG vaccine against tuberculosis: A systematic review of randomized controlled trials. Clin Infect Dis. 2014;58(4):470-80.

[31] Aaby P, Benn CS. Saving lives by training innate immunity with bacille Calmette-Guerin vaccine. Proc Natl Acad Sci U S A. 2012;109(43):17317-8.

[32] Benn CS, Netea MG, Selin LK, Aaby P. A small jab - a big effect: Nonspecific immunomodulation by vaccines. Trends Immunol. 2013;34(9):431-9.

[33] Garly M-L, Martins CL, Balé C, Baldé MA, Hedegaard KL, Gustafson P, et al. BCG scar and positive tuberculin reaction associated with reduced child mortality in West Africa: A non-specific beneficial effect of BCG? Vaccine. 2003;21(21):2782-90.

[34] Higgins JP, Soares-Weiser K, López-López JA, Kakourou A, Chaplin K, Christensen H, et al. Association of BCG, DTP, and measles containing vaccines with childhood mortality: Systematic review. Bmj. 2016;355:i5170.

[35] Hollm-Delgado MG, Stuart EA, Black RE. Acute lower respiratory infection among Bacille Calmette-Guérin (BCG)vaccinated children. Pediatrics. 2014;133(1):e73-81. 
[36] Nemes E, Geldenhuys H, Rozot V, Rutkowski KT, Ratangee F, Bilek N, et al. Prevention of M. tuberculosis Infection with H4:IC31 Vaccine or BCG Revaccination. N Engl J Med. 2018;379(2):138-49.

[37] Arts RJW, Moorlag S, Novakovic B, Li Y, Wang SY, Oosting $\mathrm{M}$, et al. BCG Vaccination Protects against Experimental Viral Infection in Humans through the Induction of Cytokines Associated with Trained Immunity. Cell Host Microbe. 2018;23(1):89-100.e5.

[38] Weiss DW, Bonhag RS, Deome KB. Protective activity of fractions of tubercle bacilli against isologous tumours in mice. Nature. 1961;190:889-91.

[39] Bast RC, Jr., Zbar B, Borsos T, Rapp HJ. BCG and cancer. N Engl J Med. 1974;290(26):1458-69.

[40] Usher NT, Chang S, Howard RS, Martinez A, Harrison LH, Santosham M, et al. Association of BCG Vaccination in Childhood With Subsequent Cancer Diagnoses: A 60-Year Follow-up of a Clinical Trial. JAMA Netw Open. 2019;2(9):e1912014.

[41] Morton DL, Eilber FR, Holmes EC, Hunt JS, Ketcham AS, Silverstein MJ, et al. BCG immunotherapy of malignant melanoma: Summary of a seven-year experience. Ann Surg. 1974;180(4):635-43.

[42] Triozzi PL, Tuthill RJ, Borden E. Re-inventing intratumoral immunotherapy for melanoma. Immunotherapy. 2011;3(5): 653-71.

[43] Lardone RD, Chan AA, Lee AF, Foshag LJ, Faries MB, Sieling PA, et al. Mycobacterium bovis Bacillus Calmette-Guérin Alters Melanoma Microenvironment Favoring Antitumor T Cell Responses and Improving M2 Macrophage Function. Front Immunol. 2017;8:965.

[44] van Puffelen JH, Keating ST, Oosterwijk E, van der Heijden AG, Netea MG, Joosten LAB, et al. Trained immunity as a molecular mechanism for BCG immunotherapy in bladder cancer. Nat Rev Urol. 2020;17(9):513-25.

[45] Morales A, Eidinger D, Bruce AW. Intracavitary Bacillus Calmette-Guerin in the treatment of superficial bladder tumors. 1976. J Urol. 2002;167(2 Pt 2):891-3; discussion 3-5.

[46] Kamat AM, Hahn NM, Efstathiou JA, Lerner SP, Malmström PU, Choi W, et al. Bladder cancer. Lancet. 2016; 388(10061):2796-810.

[47] Gofrit ON, Klein BY, Cohen IR, Ben-Hur T, Greenblatt CL, Bercovier H. Bacillus Calmette-Guérin (BCG) therapy lowers the incidence of Alzheimer's disease in bladder cancer patients. PLoS One. 2019;14(11):e0224433.

[48] Zuo Z, Qi F, Yang J, Wang X, Wu Y, Wen Y, et al. Immunization with Bacillus Calmette-Guérin (BCG) alleviates neuroinflammation and cognitive deficits in APP/PS1 mice via the recruitment of inflammation-resolving monocytes to the brain. Neurobiology of Disease. 2017;101: 27-39.

[49] Netea MG, Joosten LA, Latz E, Mills KH, Natoli G, Stunnenberg HG, et al. Trained immunity: A program of innate immune memory in health and disease. Science. 2016; 352(6284):aaf1098.

[50] van 't Wout JW, Poell R, van Furth R. The role of BCG/PPDactivated macrophages in resistance against systemic candidiasis in mice. Scand J Immunol. 1992;36(5):713-9.

[51] Quintin J, Saeed S, Martens JHA, Giamarellos-Bourboulis EJ, Ifrim DC, Logie C, et al. Candida albicans infection affords protection against reinfection via functional reprogramming of monocytes. Cell Host Microbe. 2012;12(2): 223-32.
[52] Kleinnijenhuis J, Quintin J, Preijers F, Joosten LA, Ifrim DC, Saeed S, et al. Bacille Calmette-Guerin induces NOD2-dependent nonspecific protection from reinfection via epigenetic reprogramming of monocytes. Proc Natl Acad Sci U S A. 2012;109(43):17537-42.

[53] Moorlag S, Rodriguez-Rosales YA, Gillard J, Fanucchi S, Theunissen K, Novakovic B, et al. BCG Vaccination Induces Long-Term Functional Reprogramming of Human Neutrophils. Cell Rep. 2020;33(7):108387.

[54] Kleinnijenhuis J, Quintin J, Preijers F, Joosten LA, Jacobs $\mathrm{C}$, Xavier RJ, et al. BCG-induced trained immunity in NK cells: Role for non-specific protection to infection. Clin Immunol. 2014;155(2):213-9.

[55] Zwerling A, Behr MA, Verma A, Brewer TF, Menzies D, Pai M. The BCG World Atlas: A database of global BCG vaccination policies and practices. PLoS Med. 2011;8(3): e1001012.

[56] Hamiel U, Kozer E, Youngster I. SARS-CoV-2 Rates in BCG-Vaccinated and Unvaccinated Young Adults. JAMA. 2020;323(22):2340-1.

[57] Nguyen LH, Drew DA, Graham MS, Joshi AD, Guo C-G, $\mathrm{Ma}$ W, et al. Risk of COVID-19 among front-line health-care workers and the general community: A prospective cohort study. The Lancet Public Health. 2020;5(9):e475-e83.

[58] Mazzoni A, Salvati L, Maggi L, Capone M, Vanni A, Spinicci $\mathrm{M}$, et al. Impaired immune cell cytotoxicity in severe COVID-19 is IL-6 dependent. J Clin Invest. 2020;130(9):4694-703.

[59] Giamarellos-Bourboulis EJ, Netea MG, Rovina N, Akinosoglou K, Antoniadou A, Antonakos N, et al. Complex Immune Dysregulation in COVID-19 Patients with Severe Respiratory Failure. Cell Host Microbe. 2020;27(6):9921000.e3.

[60] Braun J, Loyal L, Frentsch M, Wendisch D, Georg P, Kurth $\mathrm{F}$, et al. SARS-CoV-2-reactive T cells in healthy donors and patients with COVID-19. Nature. 2020.

[61] Mateus J, Grifoni A, Tarke A, Sidney J, Ramirez SI, Dan $\mathrm{JM}$, et al. Selective and cross-reactive SARS-CoV-2 T cell epitopes in unexposed humans. Science. 2020;370(6512): 89-94.

[62] Grifoni A, Weiskopf D, Ramirez SI, Mateus J, Dan JM, Moderbacher CR, et al. Targets of T Cell Responses to SARS-CoV-2 Coronavirus in Humans with COVID-19 Disease and Unexposed Individuals. Cell. 2020;181(7):1489501.e15.

[63] Le Bert N, Tan AT, Kunasegaran K, Tham CYL, Hafezi M, Chia A, et al. SARS-CoV-2-specific T cell immunity in cases of COVID-19 and SARS, and uninfected controls. Nature. 2020;584(7821):457-62.

[64] Lipsitch M, Grad YH, Sette A, Crotty S. Cross-reactive memory $\mathrm{T}$ cells and herd immunity to SARS-CoV-2. Nat Rev Immunol. 2020;20(11):709-13.

[65] Fjällbrant H, Ridell M, Larsson LO. Primary vaccination and revaccination of young adults with BCG: A study using immunological markers. Scand J Infect Dis. 2007; 39(9):792-8.

[66] Tomita Y, Sato R, Ikeda T, Sakagami T. BCG vaccine may generate cross-reactive $\mathrm{T}$ cells against SARS-CoV-2: In silico analyses and a hypothesis. Vaccine. 2020;38(41): 6352-6.

[67] WHO. Safety update of BCG vaccine. WHO Weekly Epidemiological Record. 2017.

[68] Hatherill M, Geldenhuys H, Pienaar B, Suliman S, Chheng P, Debanne SM, et al. Safety and reactogenicity of BCG 
revaccination with isoniazid pretreatment in TST positive adults. Vaccine. 2014;32(31):3982-8

[69] Giamarellos-Bourboulis EJ, Tsilika M, Moorlag S, Antonakos N, Kotsaki A, Domínguez-Andrés J, et al. Activate: Randomized Clinical Trial of BCG Vaccination against Infection in the Elderly. Cell. 2020;183(2):315-23.e9.

[70] Christ A, Lauterbach M, Latz E. Western Diet and the Immune System: An Inflammatory Connection. Immunity. 2019;51(5):794-811.

[71] Arts RJW, Joosten LAB, Netea MG. The Potential Role of Trained Immunity in Autoimmune and Autoinflammatory Disorders. Frontiers in Immunology. 2018;9(298).

[72] Mehta P, McAuley DF, Brown M, Sanchez E, Tattersall RS, Manson JJ. COVID-19: Consider cytokine storm syndromes and immunosuppression. Lancet. 2020;395(10229): 1033-4.

[73] Merad M, Martin JC. Pathological inflammation in patients with COVID-19: A key role for monocytes and macrophages. Nat Rev Immunol. 2020;20(6):355-62.
[74] Moorlag SJCFM, van Deuren RC, van Werkhoven CH, Jaeger M, Debisarun P, Taks E, et al. Safety and COVID-19 Symptoms in Individuals Recently Vaccinated with BCG: A Retrospective Cohort Study. Cell Reports Medicine. 2020;1(5).

[75] Koeken VA, de Bree LCJ, Mourits VP, Moorlag SJ, Walk $\mathrm{J}$, Cirovic B, et al. BCG vaccination in humans inhibits systemic inflammation in a sex-dependent manner. J Clin Invest. 2020;130(10):5591-602.

[76] Curtis N, Sparrow A, Ghebreyesus TA, Netea MG. Considering BCG vaccination to reduce the impact of COVID-19. Lancet. 2020;395(10236):1545-6.

[77] Cernuschi T, Malvolti S, Nickels E, Friede M. Bacillus Calmette-Guérin (BCG) vaccine: A global assessment of demand and supply balance. Vaccine. 2018;36(4):498-506.

[78] Bandari J, Maganty A, MacLeod LC, Davies BJ. Manufacturing and the Market: Rationalizing the Shortage of Bacillus Calmette-Guérin. Eur Urol Focus. 2018;4(4): 481-4. 